\title{
TECHNICAL EFFECIENCY OF TEA PROCESSING UNITS IN IRAN
}

\author{
Mohammad Kavoosi-Kalashami ${ }^{1}$, Parviz Shahnazari ${ }^{2}$ \\ *Corresponding authorE-mail:mkavoosi@guilan.ac.ir
}

A R T I C L E I N F O
Review Article
Received: 09 July 2018
Accepted: 11 September 2018
doi:10.5937/ekoPolj1803277K
UDC 338.439.4:633.8(55)

Keywords:

Performance, data envelopment analysis, input-oriented model, tea processing system characteristics, Iran.

JEL: C61, O12

\begin{abstract}
A B S T R A C T
This study used Data Envelopment Analysis (DEA) to measure the technical efficiency of tea processing units in Rudsar County, northern Iran. The required data sets were collected in 2014 by filling out questionnaires and interviewing with the managers of tea processing units. As an innovation, satisfaction level of the main buyer of the produced tea was considered as output in DEA model. Based on the results of CCR input-oriented model, 19\% of tea processing units with efficiency score of 1 were identified as efficient units and $81 \%$ of units had inefficient performance. The minimum technical efficiency score is equal to 0.479 and the average technical efficiency in these units is equal to 0.727 . The results of correlation analysis showed that there was a direct and significant correlation between the time of rolling and the withering temperature with the technical performance of tea processing units.
\end{abstract}

(C) 2018 EA. All rights reserved.

\section{Introduction}

Tea plantation in Iran is spread over 24 thousand hectares of northern lands. About 56 thousand households each year deliver tea leaves from their plantations to more than 160 units of tea processing units located in different counties of Guilan and Mazandaran provinces for processing (Presidential Strategic Planning and Control Office, 2015). These two provinces in northern Iran enjoy a temperate climate and fertile lands, giving them unique conditions for agricultural production like tea and related processing units (Hasanpour, 1998). Farmers deliver plucked leaves of tea to 160 tea processing units among which 148 units are located in Guilan province and 13 units in Mazandaran Province (Mahdavi and Abbasi, 2005). The process of turning green tea leaf into dry tea includes the operations of withering, rolling, fermentation, drying, sorting and packing of tea. Over $75 \%$ of the world's tea production is black, which is more than $90 \%$ in Iran (Hadipour Zimsar and et al., 2018). Black tea processing in Iran is usually done using orthodox method. In the sorting step, produced black tea categorized into different types of Ghalam, Shekasteh, Baroti and tea soil (Saberi and et al., 2012).

1 Mohammad Kavoosi-Kalashami, Ph.D., Assistant Professor, Department of Agricultural Economics, University of Guilan, Rasht, Iran, Phone: +989113317045, email: mkavoosi@guilan.ac.ir

2 Parviz Shahnazari, M.Sc., Expert in charge, Iran Tea Organization, Lahijan, Iran, Phone: +989113420090, email: P.Shahnazari@gmail.com 
The most suitable method for realizing the required growth rate in the agriculture sector is to improve and increase the efficiency and productivity of agricultural productions. Increasing efficiency can be considered as an appropriate and durable complement to a set of policies that promote the production of domestic products and promote the optimal exploitation of resources. Efficiency is a very important factor in the growth of resource productivity, especially in the agricultural economy of developing countries. On the one hand, these countries face the lack of opportunities for the development and acceptance of new technologies and, on the other hand, they do not use existing technologies efficiently (Ashrafi and et al., 2011). Increasing the efficiency of the tea processing industry can reduce the average cost of production, lower the level of tea market prices, increase demand and volume of sales, and increase the profitability of tea processing units, the outcome of which is the increase in the competitiveness of domestic tea in the market and as a result the growth of the volume of new industrial investments. Therefore, increasing the efficiency of tea processing units should be given special attention by the policy makers and economic planners of Iran. Tea imports caused Iranian consumers loyalty lost for domestic tea. However, self-sufficiency in agricultural production was always a concern for managers and planners in Iran. The importance of this issue is significant in terms of food security, job creation, the prevention of outflow of currency and its relations with other sectors and the share in Gross Domestic Production (Cheraghi and Gholipour, 2008). Tea production in Iran, due to the government's goal of self-sufficiency in the production of this product, has enjoyed a high growth since the early 1990s. This has spread due to the poor quality of green leaves, the processing, packaging and supply of tea. Thus, by supplying the products produced by this project, a sharp decrease in the purchase and consumption of domestic tea was observed due to its poor quality and dissatisfaction by consumers. Government policies caused the producers to not pay attention to investing in repairing and rehabilitating tea plantations and also, using old and depreciated technologies in processing black tea units (Sepehrdoust and Dastjerdi, 2013). Therefore, increasing the efficiency of tea processing units should be aimed at increasing the quality of production. The use of modern and appropriate technology in the coordinated set and the combination of factors of production and the proper allocation of inputs in an efficient management can play a significant role in this regard.

The fourth and fifth programs of economic, social and cultural development of Iran emphasized on the promotion of the share of efficiency and productivity of production factors in the economic growth of all sectors of the economy especially agriculture sector. Therefore, in the first step, awareness of the status of technical performance of production units and assessment of their condition is essential. Guilan and Mazandaran Provinces in northern Iran with moderate climate, fertile lands, rich soil and the ability to produce high quality agricultural products have unique features in the agricultural and related industries of this sector and therefore had the most suitable and prerequisite conditions for green tea leaf cultivation in Iran (Hasanpour, 1998). Iran's tea industry is particularly important among economic activities in terms of production and 
employment. Increasing the production and improvement of the tea industry is not only in order to achieve economic growth and welfare in the region, but also had high interdependence with the independence and self-sufficiency of the economy, social justice, national and social aspirations. Iran's tea industry has less dependence on the foreign countries and can play an important role in generating employment and activating the business sector at the national level (Mahdavi and Abbasi, 2005). The present study investigates the technical efficiency of tea processing units in Rudsar County, northern Iran. Considering the different quality of products in the tea processing units, in this study as an innovation, the satisfaction of the main buyers from the quality of tea was also considered as one of the outputs in performance analysis.

The enhancement of efficiency in different sectors can pave the way for economic development and social welfare. Sustainability of tea plantation and processing in northern Iran is of particular importance. Improving technical performance of tea processing units enable competitiveness of Iranian tea and maintain market share of this product that ultimately sustain tea plantation and processing in northern Iran as a strategic business. This study investigates technical performance of tea processing units in Rudsar County, northern Iran and identifies the drivers of technical performance in tea industry of this region.

\section{Literature Review}

Few researches have been done in the field of economics and management of tea processing units. Qin and Zhou (1992) found that tea processing units energy use in rural areas of China was a function of the type of final product, tea cultivar and processing equipment. Wadonda (1998) showed that during the years 1984-88, the highest technical efficiency of the Malaysian tea industry was $72 \%$ in 1984 . Also, the industry's lowest performance (44\%) was in 1988. Gholizadeh and et al. (2008), investigated productivity and factors affecting it in the tea processing industries of Iran. In this regard, data set for 55 tea processing units and the mathematical optimization model were used. The results showed that the average productivity of the studied units was $71 \%$. The number of productive units is $24 \%$ and the number of non-productive units is $76 \%$. The lack of quality green tea leaves, low level of staff training and their professional skills are among the most important reasons for low productivity of these units. Taulo and Sebitosi (2013) present a method using index decomposition analysis (IDA), data envelopment analysis (DEA) and evolutionary algorithms for generating efficient frontiers in multi-objective optimization problems. The purpose of DEA is to measure the relative efficiency of decision making units and reflects the various preferences of decision makers. The index decomposition analysis aims at understanding the characteristics that underline changes in energy intensity at factory level. In addition, an evolutionary algorithm is used for directly finding Pareto optimal solutions. In this paper, we propose to combine DEA and EA and search for optimal solutions. Data from three Malawian tea factories has been used to test the effectiveness of the proposed method and the energy performance across the factories has been 
evaluated. Hadipour Zimsar and et al. (2018) identify and analyze factors determining energy efficiency in tea processing units of Guilan Province, northern Iran. Results showed that the correct and sound design of the new hot air furnaces, the enhancement of technical knowledge of technicians in withering, fermentation, drying and storage units and optimum scheduling of withering operation with respect to the final status of green tea leaf were found to be the most important technical, managerial-policy and knowledge-skill factors determining the improvement of energy productivity in tea factories of Guilan Province.

\section{Materials and methods}

Data Envelopment Analysis (DEA) is a linear programming method that uses the information of organizations and production units as Decision Making Units (DMU) to make the efficient frontiers. The mentioned frontier is based on DMU's information in the form of inputs and outputs and based on sequential linear programming results, and in fact the ineffectiveness of each DMU depends on the distance between the unit to the efficient frontier (Azar and Moetameni, 2004). This method can involve multiple outputs and inputs without the need for pre-determined weights (as opposed to the index method) and without the need for clear specifications of the relationships between inputs and outputs (as opposed to the regression method) (Mehrgan, 2004). Data envelopment analysis has become one of the most common performance evaluation methods with unique capabilities, and many researches in this area have tried to measure performance using this method (Azimi and et al., 2017; Tsuar and et al., 2017).

In order to measure the technical efficiency of tea processing units, the model provided by Charnes, Cooper and Rhodes, known as the CCR, was used (Charnes et al., 1978). Constant Return to Scale (CRS) means that every multiple of inputs produces the same multiple of outputs. In this model, by changing a unit in the inputs, the outputs also change with a constant (decreasing or increasing) ratio. In fact, the slope of the production function in this model is constant (Coelli, 2008). The calculation of the return to scale model for $\mathrm{K}$ inputs and $\mathrm{M}$ outputs that exists for each tea processing units will be as follows (Emami Meybodi, 2005):

$$
\begin{aligned}
& \operatorname{Max} \frac{U^{\prime} Y_{i}}{V^{\prime} X_{i}} \\
& \text { Subject to : } \\
& \frac{U^{\prime} Y_{i}}{V^{\prime} X_{i}} \leq 1 \\
& U \geq 0, V \geq 0
\end{aligned}
$$

In which, $U$ was $M \times 1$ vector of outputs weights, $V$ was $K \times 1$ vector of inputs weights, $\mathrm{U}^{\prime}$ and $\mathrm{V}^{\prime}$ were transpose vectors for $\mathrm{U}$ and $\mathrm{V}, \mathrm{X}$ represented for $\mathrm{M} \times \mathrm{K}$ matrix of inputs levels and $\mathrm{Y}$ showed $\mathrm{M} \times \mathrm{N}$ matrix of outputs levels. Matrixes $\mathrm{X}$ and $\mathrm{Y}$ represent all 
information for the $\mathrm{N}$ tea processing units (DMU). The above pattern has an enormous number of optimal solutions. To avoid this problem, the restriction $\mathrm{V}^{\prime} \mathrm{X}_{\mathrm{i}}=1$ is imposed on the model (Emami Meybodi, 2005):

$$
\begin{aligned}
& \operatorname{Max}_{\mu, \mathrm{V}}\left(\mu^{\prime} \mathrm{Y}_{\mathrm{i}}\right) \\
& \text { Subject to: } \\
& \mathrm{V}^{\prime} \mathrm{X}_{\mathrm{i}}=1, \\
& \mu^{\prime} \mathrm{Y}_{\mathrm{j}}-\mathrm{V}^{\prime} \mathrm{X}_{\mathrm{j}} \leq 0, \quad \mathrm{j}=1,2, \ldots, \mathrm{N} \\
& \mu, \mathrm{V} \geq 0,
\end{aligned}
$$

In linear programming, generally imposing fewer constraints makes it easier to solve the problem. The use of the dual form delivers the technical efficiency level $(\theta)$ for each tea processing units, separately. Hence, in general the following pattern is most often used (Jahanshahlo and et al., 2007):

$$
\begin{aligned}
& \operatorname{Min}_{\theta, \lambda} \theta, \\
& \text { Subject to : } \\
& -\mathrm{y}_{\mathrm{i}}+\mathrm{Y} \lambda \geq 0, \\
& \theta \mathrm{x}_{\mathrm{i}}-\mathrm{X} \lambda \geq 0, \\
& \lambda \geq 0,
\end{aligned}
$$

In which, $\theta$ was quantitative amount and $\lambda$ was $\mathrm{N} \times 1$ vector of constant levels.

The inputs included in the study were the processing unit production costs and the cost of buying green tea leaves from framers. Also, the outputs included in the modeling were the value of the tea processing unit's total production, and the degree of satisfaction of the main purchaser of tea from the processing unit. Due to the different quality of the tea product, the buyers' satisfaction with this product is very important. In order to measure the satisfaction of the major buyer of tea for each processing unit, the use of the Likert spectrum was considered.

The required information in this study was collected by questionnaires and survey. The questionnaire for tea processing units was designed in two sections. In the first section, the demographic characteristics of the manager include age, gender, education, etc. were questioned and also the characteristics of employees were studied include the number of skilled and unskilled labors in the processing unit, the education level of employees, the production experience and the wages of the employed individuals. The second part of the questionnaire was devoted to production costs including fuel, water, electricity, depreciation and etc. and processing unit revenues including sales of various tea qualities. Satisfaction of the major buyer of tea from each processing unit was also questioned by telephone. The required data sets were collected at 2014. 


\section{Results and Discussions}

The main research tool in this study was a questionnaire. In order to ensure its validity, its copies were provided to 10 experts of the Iran Tea Organization (ITO), and modifications were made based on their feedback. In order to ensure reliability of the research tool, the designed questionnaire was administered to 10 tea processing units. The reliability of the study tool was evaluated by Cronbach's alpha test ( $\alpha$ value equals to 0.83 ), implying the questionnaire reliability. Data set were analyzed using SPSS $_{20}$ and DEAP software packages.

The study of the characteristics of employees working in tea processing units showed that among 16 managers in the studied units, according to age groups, most of the managers $(50 \%)$ were in the age group of 50 to 60 years. The youngest manager was 45 years old, and the oldest was 68 years old. All managers of tea processing units in the Rudsar County were male. Most of the managers of these units $(62.4 \%)$ had a university degree. In the studied tea processing units, skilled labors were responsible for guiding and leadership of unskilled labors. The average number of skilled labors in the studied processing units was 3.75 workers with the minimum number of 2 and maximum number of 4 workers. The average number of unskilled labors was 46.06 workers with the minimum number of 25 and maximum number of 75 workers. The whole unskilled labors at the studied tea processing units had education level of under the diploma (78\%) and diploma (22\%). Most of skilled labors (93.7\%) had more than 6 years' experience in tea processing units. Monthly income for most of skilled labors (93.7\%) was more than 10 Million Rials while most of unskilled labors (93.7\%) received less than 7.5 Million Rials per a month of working (shown in Table 1).

Table 1. Frequency distribution of employees' characteristics in tea processing units.

\begin{tabular}{|c|c|c|c|c|c|}
\hline Characteristic & Level & Frequency & Percent (\%) & Average & S.D. \\
\hline \multirow{2}{*}{ Manager Gender } & Male & 16 & 100 & & \\
\hline & Female & 0 & 0 & & \\
\hline \multirow{4}{*}{ Manager Age (years) } & & & & 56.47 & 7.78 \\
\hline & $<50$ & 4 & 25 & & \\
\hline & $50-60$ & 8 & 50 & & \\
\hline & $>60$ & 4 & 25 & & \\
\hline \multirow{4}{*}{ Manager Education level } & Under the diploma & 1 & 6.3 & - & - \\
\hline & Diploma & 5 & 31.3 & & \\
\hline & Associate & 6 & 37.4 & & \\
\hline & Bachelor & 4 & 25 & & \\
\hline \multirow{4}{*}{$\begin{array}{l}\text { Management Experience } \\
\text { (years) }\end{array}$} & & & & 11.12 & 4.55 \\
\hline & $<8$ & 2 & 12.5 & & \\
\hline & $8-13$ & 10 & 62.5 & & \\
\hline & $>13$ & 4 & 25 & & \\
\hline
\end{tabular}




\begin{tabular}{|c|c|c|c|c|c|}
\hline \multirow{4}{*}{$\begin{array}{c}\text { Skilled labor education } \\
\text { level }\end{array}$} & Under the diploma & 1 & 6.3 & - & - \\
\hline & Diploma & 10 & 62.4 & & \\
\hline & Associate & 4 & 25 & & \\
\hline & Bachelor & 1 & 6.3 & & \\
\hline \multirow{4}{*}{$\begin{array}{c}\text { Skilled labor experience } \\
\text { (years) }\end{array}$} & & & & 10.33 & 3.6 \\
\hline & $<6$ & 1 & 6.3 & & \\
\hline & $6-10$ & 11 & 68.7 & & \\
\hline & $>10$ & 4 & 25 & & \\
\hline \multirow{4}{*}{$\begin{array}{l}\text { Monthly income of a } \\
\text { skilled labor } \\
\text { (Million Rials) }\end{array}$} & & & & 11.5 & 1.2 \\
\hline & $<10$ & 1 & 6.3 & & \\
\hline & $10-12$ & 12 & 75 & & \\
\hline & $>12$ & 3 & 18.7 & & \\
\hline \multirow{4}{*}{$\begin{array}{l}\text { Monthly income of an } \\
\text { unskilled labor } \\
\text { (Million Rials) }\end{array}$} & & & & 7.4 & 0.2 \\
\hline & $<7.2$ & 3 & 18.7 & & \\
\hline & $7.2-7.5$ & 12 & 75 & & \\
\hline & $>7.5$ & 1 & 6.3 & & \\
\hline
\end{tabular}

Investigating the cost components of the studied tea processing units in a production period (6 months) showed that in average, the labor costs had the highest cost share $(45.58 \%)$ and the cost of water supply had the least cost share $(0.05 \%)$ among the different cost items (shown in Table 2).

Table 2. Frequency distribution of cost components and revenue of tea processing units.

\begin{tabular}{|c|c|c|c|c|c|}
\hline Item & Level & Frequency & Percent (\%) & Average & S.D. \\
\hline \multirow{4}{*}{$\begin{array}{l}\text { Skilled labor cost } \\
\text { (Million Rials) }\end{array}$} & & & & 261 & 47.15 \\
\hline & $<240$ & 4 & 25 & & \\
\hline & $240-288$ & 4 & 25 & & \\
\hline & $>288$ & 8 & 50 & & \\
\hline \multirow{4}{*}{$\begin{array}{l}\text { Unskilled labor cost } \\
\text { (Million Rials) }\end{array}$} & & & & 2044.59 & 742.74 \\
\hline & $<1350$ & 3 & 18.75 & & \\
\hline & $1350-2700$ & 8 & 50 & & \\
\hline & $>2700$ & 5 & 31.25 & & \\
\hline \multirow{4}{*}{$\begin{array}{c}\text { Fuel cost } \\
\text { (Million Rials) }\end{array}$} & & & & 45.37 & 32.98 \\
\hline & $<20$ & 6 & 37.5 & & \\
\hline & $20-40$ & 2 & 12.5 & & \\
\hline & $>40$ & 8 & 50 & & \\
\hline \multirow{4}{*}{$\begin{array}{l}\text { Electricity cost } \\
\text { (Million Rials) }\end{array}$} & & & & 20.97 & 12.46 \\
\hline & $<10$ & 4 & 25 & & \\
\hline & $10-20$ & 4 & 25 & & \\
\hline & $>20$ & 8 & 50 & & \\
\hline
\end{tabular}




\begin{tabular}{|c|c|c|c|c|c|}
\hline Item & Level & Frequency & Percent (\%) & Average & S.D. \\
\hline \multirow{4}{*}{$\begin{array}{l}\text { Water supply cost } \\
\text { (Million Rials) }\end{array}$} & & & & 16 & 2.7 \\
\hline & $<10$ & 9 & 56.25 & & \\
\hline & $10-20$ & 3 & 18.75 & & \\
\hline & $>20$ & 4 & 25 & & \\
\hline \multirow{4}{*}{$\begin{array}{l}\text { Maintenances cost } \\
\text { (Million Rials) }\end{array}$} & & & & 31.12 & 24.15 \\
\hline & $<20$ & 8 & 50 & & \\
\hline & $20-40$ & 3 & 18.75 & & \\
\hline & $>40$ & 5 & 31.25 & & \\
\hline \multirow{4}{*}{$\begin{array}{c}\text { Revenue } \\
\text { (Billion Rials) }\end{array}$} & & & & 15.7 & 12.98 \\
\hline & $<10$ & 8 & 50 & & \\
\hline & $10-20$ & 3 & 18.75 & & \\
\hline & $>20$ & 5 & 31.25 & & \\
\hline \multirow{5}{*}{$\begin{array}{l}\text { Satisfaction of the main } \\
\text { buyer }\end{array}$} & Very Satisfied & 2 & 12.5 & - & - \\
\hline & Satisfied & 7 & 43.75 & & \\
\hline & Borderline & 3 & 18.75 & & \\
\hline & Dissatisfied & 3 & 18.75 & & \\
\hline & Very dissatisfied & 1 & 6.25 & & \\
\hline
\end{tabular}

The results of the CCR model showed that $19 \%$ (3 processing units) were efficient and $81 \%$ (13 processing units) had inefficient performance (shown in Table 3 ). To reach the efficiency frontier, the inefficient units could benchmark the efficient units (Peers).

Table 3. Technical Efficiency (TE) of tea processing units.

\begin{tabular}{|c|c|c|c|}
\hline Units & TE Score & Peer 1 & Peer 2 \\
\hline 1 & 1 & - & - \\
\hline 2 & 0.699 & 10 & 1 \\
\hline 3 & 0.324 & 1 & 7 \\
\hline 4 & 0.754 & 1 & 7 \\
\hline 5 & 0.508 & 7 & \\
\hline 6 & 0.537 & 1 & 7 \\
\hline 7 & 1 & - & - \\
\hline 8 & 0.732 & 7 & 10 \\
\hline 9 & 0.672 & 7 & 10 \\
\hline 10 & 1 & - & - \\
\hline 11 & 0.968 & 7 & 10 \\
\hline 12 & 0.479 & 7 & 1 \\
\hline 13 & 0.811 & 1 & 7 \\
\hline 14 & 0.959 & 7 & \\
\hline 15 & 0.494 & 1 & 7 \\
\hline 16 & 0.689 & 1 & 7 \\
\hline
\end{tabular}

The average TE score of the studied units was 0.727 , which suggests an increase of $27.3 \%$ of output without increasing inputs in case of efficient operation of all tea processing units. 
In order to evaluate the effectiveness of the processing system characteristics on the efficiency score of the studied units, the correlation analysis was used (shown in Table 4).

Table 4. Correlation of processing system characteristics with TE in tea processing units.

\begin{tabular}{|c|c|c|c|c|}
\hline Variable & Scale & Test & Coefficient & P-Value \\
\hline Lifetime of processing devices & Ratio & Pearson & -0.125 & 0.644 \\
\hline Education level of manager & Ordinal & Spearman & 0.310 & 0.243 \\
\hline Experience of manager & Ratio & Pearson & 0.227 & 0.397 \\
\hline Rolling duration of young apical shoots & Ratio & Pearson & 0.502 & 0.047 \\
\hline Rolling duration of mature leaves & Ratio & Pearson & 0.119 & 0.662 \\
\hline Withering temperature of first flush tea leaves & Interval & Spearman & 0.001 & 0.99 \\
\hline Withering temperature of second flush tea leaves & Interval & Spearman & 0.467 & 0.038 \\
\hline Withering temperature of third flush tea leaves & Interval & Spearman & 0.545 & 0.029 \\
\hline
\end{tabular}

The results showed that the rolling duration of young apical shoots (soft leaves) had a significant effect on the technical performance of the tea processing units. There was a direct and statistically significant correlation between the rolling duration of young soft leaves and TE of tea processing units at 5\% level. Also, withering temperature of first and second flush tea leaves was also effective on the technical performance of these units. There was a direct and statistically significant correlation between these temperatures and TE of tea processing units at the 5\% level. The correlation coefficients for rolling duration of young apical shoots and withering temperature of third flush tea leaves showed relatively strong correlation with TE but the coefficient of withering temperature of second flush tea leaves revealed moderate correlation with TE of tea processing units.

\section{Conclusions}

Given the level of competition in the tea market of Iran, the goal of tea processing units is to attract more resources and reduce costs, and most importantly, increase efficiency and income generation. Effective units have better performance in resource absorption, optimal allocation of resources, and optimal production. To determine the key variables of the tea processing units' efficiency is imperative to account the combined effects of the inputs interaction beside the buyers' satisfaction of tea quality. Regarding the efficiency scores and the results of correlation analysis, it can be claimed that factors such as technical knowledge of labors and the observance of specialized processing principles have a significant effect on the efficiency or inefficiency performance of the units and lead to increased efficiency and income. Regarding the fact that in this study, rolling duration and withering temperature had statistically significant correlations with the technical performance of tea processing units, it is recommended that by conducting training classes and upgrading the technical knowledge of the labors in the processing units, the production of quality tea to be realized. The review of lessons learned by leading tea manufacturing countries like Indian and China would be useful in this way. Increasing farmers' awareness of lopping and trimming has a significant role in the quality of tea production and improves the effectiveness of the rolling and withering 
processes and ultimately has a direct effect on the better sale of produced tea. This requires more and better supervision of professional experts on tea plantations and farmers works. The technical support of the Iran's tea organization, the technical skills of the experts, the supervision of the responsible purchasing officer on the quality of the green leaves, the communication skills of the experts with the farmers, the proportion of training courses held with the needs of experts, are also among important factors affecting the performance of the tea processing units in Iran.

\section{Conflict of interests}

The authors declare no conflict of interest.

\section{References}

1. Ashrafi, V., Mirzaei Chalak, M., Zebardast, A. (2011). Investigating technical, allocative and economic efficiency of Iran's wheat production. Regional Conference of Agricultural Development in North-West Provinces of Iran, 9-10 November 2011, Meshginshahr, Iran.

2. Azar, A., Moetameni, A. (2004). Measuring firms' productivity using Data Envelope Analysis (DEA). Journal of Education and Learning, 11, 41-54.

3. Azimi, R., Allahyari, M.S., Damalas, C.A., Kavoosi-Kalashami, M., (2017). Technical performance of Plant Clinics as providers of crop protection services: The case of Guilan Province, Iran. Crop Protection, 101, 12-18.

4. Charnes, A., Cooper, W.W., Rhodes, E. (1978). Measuring the Efficiency of Decision Making Units. European Journal of Operational Research, 2, 429444.

5. Cheraghi, D., Gholipour, S. (2008). Investigating the effect of economic policies on tea market adjustment in Iran. Journal of Commerce Studies, 37 , 27-42.

6. Coelli, T.J. (2008). A guide to DEAP version 2.1. Center for Efficiency and productivity Analysis (CEPA), Working papers 96/08.

7. Emami Meybodi, A. (2005). The principles of efficiency and productivity measurement. Commerce Studies and Researches Institute Press, Tehran, Iran.

8. Hadipour Zimsar, S., Firouzi, S., Allahyari, M.S. (2018). Enhancers of the energy efficiency in tea processing industry. Energy Equipment and Systems, 6(2), 201-209.

9. Hasanpour, M. (1998). Tea Cultivation and Technology. University of Guilan's Press.

10. Presidential Strategic Planning and Control Office, (2015). Report on the Iran's tea industry.

11. Gholizadeh, M.H., Abbasi, R., Ebrahimpour Azbari, M., Mahdavi, R. (2008). Measurement and analysis of effective factors on the productivity of Iranian tea industry. Agricultural Economics and Development, 67, 19-39. 
12. Jahanshahlo, G., Hossienzadeh Lotfi, F., Nikmaram, H. (2007). Data envelope analysis and its applications, Asar Nafis Press, Tehran, Iran.

13. Mahdavi, R. and Abbasi, R. (2005). Measuring and analyzing the productivity of tea industry in Guilan Province, Iran, Guilan Province Management and Planning Organization Press.

14. Mehrgan, M.R. 2004. Quantitative models for evaluating organizations performance, University of Tehran Press, Tehran, Iran.

15. Qin, N.J., Zhou, H. (1992). Energy consumption and conservation in tea processing in China. Renewable Energy, 2(1), 1-5.

16. Saberi, S., Almasi, M., Minaei, S., Bakhoda, H., Salarian, M.B. (2012). Investigating wastes in tea processing units of Tonekabon county. National Conference on Sustainable Development, 10 March 2012, Tehran, Iran.

17. Sepehrdoust, H., Dastjerdi, H. (2013). Investigating the technical efficiency of agriculture subsectors using the window analysis method. Journal of Agricultural Science and Sustainable Production, 41, 131-141.

18. Taulo, J.L., Sebitosi, A.B. (2013). Improving energy efficiency in Malawian tea industries using an integrated multi-objective optimization method combining IDA, DEA and evolutionary algorithms. Industrial and commercial use of energy conference (ICUE), 20-21 August 2013, Cape Town, South Africa.

19. Tsaur, R.C., Chen, I.F., Chan, Y.S. (2017). TFT-LCD industry performance analysis and evaluation using GRA and DEA models. International Journal of Production Research, 55(15), 4378-4391.

20. Wadonda, C.E. (1998). Technical efficiency in manufacturing industries in Malawi using deterministic production frontier, University of Malawi and Wadonda Consult, Working Paper No. WC/05/981998. 